\title{
Avaliação da capacitação espermática in vitro pela reação acrossômica e viabilidade, em sêmen de touros Guzerá
}

\section{Evauation of in vitro sperm capacitation by acrossome reation and viability, in semen of Guzera bulls}

\author{
Sá, W.F., ${ }^{*},{ }^{* *}$ Leite, V., ${ }^{*},{ }^{* *}$ Camargo, L.S.A., ${ }^{*}$ Ferreira, A.M., ${ }^{*}$ Viana, J.H.M., ${ }^{*}$ Nogueira, L.A. ${ }^{* *}$ Ramos, A.A. ${ }^{*}$
}

\begin{abstract}
Resumo
O objetivo deste trabalho foi avaliar a capacitação espermática pela reação acrossômica e viabilidade espermática de sêmen de touros Guzerá. Utilizou-se sêmen de diferentes touros adquiridos de centrais de inseminação artificial. Após o descongelamento, o sêmen foi incubado inicialmente com 0 (T1) e $10 \mathrm{mg} / \mathrm{ml}$ (T2) de heparina por quatro horas a $39^{\circ} \mathrm{C}$ e $95 \%$ de umidade, e posteriormente com lisofosfatidilcolina por mais 15 minutos, para indução da reação acrossômica. Antes e após o período de incubação foram feitas lâminas para a análise da viabilidade espermática e reação acrossômica. Verificou-se que o tratamento com heparina aumentou a taxa de espermatozóides com reação acrossômica $(p<0,05)$, e que houve diferenças na fertilidade entre os touros após a capacitação espermática. Conclui-se que o teste de reação acrossômica e viabilidade espermática pode ser utilizado para avaliação da capacitação espermática in vitro de touros da raça Guzerá.
\end{abstract}

Palavras-chave: bovino, capacitação espermática, reação acrossômica

\begin{abstract}
The aim of this study was evaluated in vitro sperm capacitation though acrosome reaction and viability of Guzera bulls. It was utilized semen from different bulls and freezed in Artificial Insemination Companies. After thawing, the semen was incubated with 0 (T1) and $10 \mathrm{mg} / \mathrm{ml}$ (T2) de heparin for four hours, and incubated again with lysophosphatidilcholine for more 15 minutes, to induce the acrosome reaction. Before and after incubation time microscope glass-slides were made with semen samples to analyze sperm viability and acrosome reaction. It was observed that the treatment with heparin increased the acrosome reaction rate $(p<0,05)$, and that there was difference for bulls after sperm capacitation $(p<0,05)$. It was concluded that in vitro acrosome reaction and sperm viability could be used to evaluate in vitro sperm capacitation for Guzera breed bulls.
\end{abstract}

Keywords: bovine, sperm capacitation, acrosome reaction.

\section{Introdução}

O mecanismo da capacitação espermática e da reação acrossômica (RA) é pouco conhecido. A capacitação espermática compreende alterações fisiológicas que conferem competência ao espermatozóide em penetrar e fecundar o oócito (Dasgupta et al., 1994).

O teste de indução da reação acrossômica in vitro é um método utilizado para a avaliação da capacitação espermática, e que possui uma alta correlação com a fertilidade a campo (Blottner et al., 1990). A RA pode ser induzida in vitro pela lisofosfatidilcolina (LC) (Parrish et al., 1988), após capacitação espermática provocada pela heparina (Miller et al., 1990). A LC tem sido usada na concentração de $100 \mathrm{mg} / \mathrm{ml}$ por 15 minutos, após a incubação do sêmen com heparina por quatro horas (Parrish et al., 1988; Thérien et al., 1995). A heparina é a substância mais eficiente para induzir capacitação espermática e, conseqüentemente, a RA in vitro (Fukui et al., 1990; Cox et al., 1994). Segundo Whitfield e Parkinson (1992), $10 \mathrm{mg} / \mathrm{ml}$ de heparina induzem a capacitação e RA em espermatozóides bovinos. A manutenção da viabilidade do espermatozóide capacitado também é importante para o sucesso da fecundação (Way et al., 1994). A percentagem de espermatozóides vivos na fecundação in vitro possui correlação positiva com o potencial de fertilidade in vitro de um touro (Tanghe et al., 2002).

Devido à necessidade da capacitação espermática para a fecundação, é importante fazer a avaliação antes de procedimentos de fecundação in vitro (FIV), para maior eficiência da produção in vitro de embriões (PIV). O uso da avaliação de RA e viabilidade espermática auxilia na seleção do sêmen a ser utilizado para a PIV.

Como a raça Guzerá e seus cruzamentos vem surgindo como uma boa opção para produção de leite nos trópicos, aumen-

*Embrapa Gado de Leite - Juiz de Fora , MG

**Universidade Federal Fluminense - Niterói, RJ

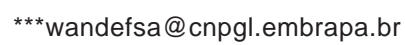


tando sua importância no rebanho nacional, torna-se necessário o conhecimento do comportamento do sêmen de touros dessa raça em procedimentos de capacitação espermática in vitro, pelas diferenças fisiológicas existentes entre as subespécies bovinas quanto à secreção hormonal (Randel, 1984), sensibilidade a hormônios externos (Munro, 1986) e comportamento social e sexual (Galina et al., 1995), contribuindo assim para a adaptação da técnica de PIV para essa raça. O objetivo do trabalho foi avaliar a capacitação espermática in vitro de sêmen de touros Guzerá pela RA e viabilidade espermática.

\section{Material e métodos}

Utilizou-se sêmen congelado de três touros Guzerá, adquiridos em centrais de inseminação artificial e estocados em nitrogênio líquido. O sêmen foi descongelado em banho-maria a $37^{\circ} \mathrm{C}$ por 30 segundos, após o que avaliou-se sua motilidade e vigor, pelo exame em lâmina aquecida e lamínula. Para cada observação foram utilizadas três palhetas de sêmen, com dez repetições por touro.

O sêmen descongelado era depositado num tubo de centrífuga e diluído em meio Talp Hepes na proporção 1:10 e centrifugado a $300 \mathrm{~g}$ por dez minutos. Desprezou-se o sobrenadante e ressuspendeu-se o sedimento com Talp Hepes na proporção 1:10 para uma nova lavagem nas mesmas condições descritas anteriormente. Após desprezar o sobrenadante dessa segunda lavagem, o sedimento foi novamente ressuspendido com Talp Hepes, na proporção 1:1. Preparando-se esfregaços corados com eosina-negrosina (Dott e Foster, 1972) para avaliação da viabilidade espermática e naftol amarelo e eritrosina B para avaliação da RA (tempo de incubação 0h). A concentração espermática foi determinada pela contagem de células na câmara de Newbauer, e a concentração ajustada para $20 \times 10^{6}$ células/ml de solução, para cada tratamento. O sêmen foi distribuído em dois tratamentos: T1 (0 mg/ml de heparina) e T2 (10 mg/ml de heparina), e mantido em estufa a $39^{\circ} \mathrm{C}$ por quatro horas e avaliou-se novamente a RA. A seguir, adicionaram-se $100 \mathrm{mg} / \mathrm{ml}$ de lisofosfatidilcolina ${ }^{1}$ a cada tratamento, após o qual os tubos voltaram para a estufa por mais 15 minutos, sob as mesmas condições descritas anteriormente. Prepararam-se, então, os esfregaços e avaliaram-se as taxas de viabilidade espermática e de RA(tempo de incubação 4h15).

Nas lâminas coradas com eosina-negrosina, contavam-se 100 células, para se avaliar o percentual de espermatozóides vivos (viabilidade espermática) ou mortos. Definiu-se como células viáveis aquelas que não coraram, apresentando apenas coloração de fundo na lâmina (acinzentado), e como nãoviáveis aquelas que se coram total ou parcialmente. Nas lâminas coradas com naftol amarelo-eritrosina B, contavam-se 200 células para determinar o percentual de espermatozóides com acrossoma intacto ou espermatozóides com reação do acrossoma. Ao ler acrossoma "intacto", deve-se entender como presença do acrossoma.

Definiu-se como células com acrossoma íntegro e que não sofreram RA, aquelas de coloração avermelhada, com ápice proeminente e bem definido. As células que sofreram RA apresentavam coloração clara e sem o contorno acrossomal.

\footnotetext{
${ }^{1}$ L-a-lysophosphatidilcholine - L4129 - St. Louis, MO, USA
}

Os dados foram submetidos à análise de variância, usandose o procedimento GLM (General Linear Models) do SAS (1987), com delineamento fatorial 3x2 (três touros e duas concentrações de heparina), e as médias comparadas pelo teste de Turkey. As variáveis - viabilidade espermática e espermatozóides com reação acrossômica sofreram transformação angular.

\section{Resultados e discussão}

A Tabela 1 mostra o efeito da capacitação espermática com heparina sobre a taxa de espermatozóide com reação acrossômica, em touros da raça Guzerá.

Comparando-se a taxa de reação acrossômica em meios com e sem heparina, verifica-se um número maior de espermatozóides com reação acrossômica na presença dessa substância $(p<0,05)$. De acordo com a literatura (Miller et al., 1990; Gliedt et al., 1996; McCauley et al., 1996), a presença de heparina mostrou-se eficaz na capacitação de espermatozóides, predispondo-os a sofrerem reação acrossômica. A menor taxa de espermatozóides com reação acrossômica no T1 pode ser em virtude da LC possuir pouca ação sobre os espermatozóides não-capacitados, com mais espermatozóides prontos para reagir no T2. Entretanto, o aumento no percentual de células com reação acrossômica às $4 \mathrm{~h} 15$, com relação à taxa inicial (0h), no tratamento sem heparina, sugere que o próprio tempo de incubação ou outra substância presente no meio de incubação podem também capacitar espermatozóides bovinos e provocar reação acrossômica, embora em taxa menor do que com a heparina. Pereira et al. (2000) observaram um pequeno aumento na RA de espermatozóides bovinos incubados por 30 minutos com heparina, na ausência de um agente indutor. Os autores consideram este aumento como resultado de uma RA induzida pela heparina. Alguns trabalhos indicam que, ao se deixar sêmen não-diluído de carneiros em temperatura ambiente (escuro) por quatro horas, é possível induzir capacitação em aproximadamente 50\% dos espermatozóides (Pérez et al., 1997) ou que a simples lavagem dos espermatozóides provocará a remoção das proteínas do plasma seminal da superfície de sua membrana, permitindo o início da capacitação (Miller e Hunter, 1986). Segundo Rajamahendran et al. (1994) pode ocorrer reação acrossômica espontaneamente após longos períodos de incubação.

Verifica-se, portanto, a necessidade do uso da heparina para a capacitação espermática do sêmen da raça Guzerá para otimização da reação acrossômica, o que se mostrou semeIhante a outras raças (Whitfield e Parkinson, 1992; Sá et al., 2002 ). Para Blotter et al. (1990); Bellin et al. (1994) e McCauley et al. (1996), espermatozóides de touros com alta fertilidade sofrem reação acrossômica com mais freqüência, por apresentarem maior afinidade na ligação com a heparina. Esta acelera a conversão da proacrosina zimógena em acrosina, iniciando a digestão da membrana plasmática, e por si só é capaz de desencadear a perda acrossômica em algumas células (Leclerc et al., 1989; Mark e Ax, 1985).

A Figura 1 mostra as taxas de viabilidade espermática e reação acrossômica para cada touro analisado. Observa-se que o touro $\mathrm{C}$ apresentou melhor taxa de viabilidade espermática e de reação acrossômica após a capacitação espermática in vitro $(P<0,05)$. Com base nesses resultados, o touro $C$ esta- 
Tabela 1 - Taxa de espermatozóides viáveis e com reação acrossômica de acordo com os tratamentos de heparina.

\begin{tabular}{c|c|c|c|c|c|c}
\hline Tratamento & $\begin{array}{c}\mathrm{N}^{0} \text { de } \\
\text { observações }\end{array}$ & \multicolumn{2}{|c|}{$\begin{array}{c}\text { Viabilidade espermática } \\
(\%)\end{array}$} & \multicolumn{3}{|c}{ Espermatozóides com RA ${ }^{1}(\%)$} \\
\hline & & $0 \mathrm{~h}$ & $4: 15 \mathrm{~h}$ & $0 \mathrm{~h}$ & $4: 00 \mathrm{~h}$ & $4: 15 \mathrm{~h}$ \\
\hline $\mathrm{T} 1(0 \mu \mathrm{g} / \mathrm{ml}$ de heparina $)$ & 30 & 82,0 & $73,0^{\mathrm{a}}$ & 20,0 & 43,92 & $48,0^{\mathrm{a}}$ \\
\hline $\mathrm{T} 2(10 \mu \mathrm{g} / \mathrm{ml}$ de heparina) & 30 & 82,0 & $72,0^{\mathrm{a}}$ & 20,0 & 43,50 & $54,0^{\mathrm{b}}$ \\
\hline
\end{tabular}

Médias com letras diferentes na mesma coluna diferem entre si $(P<0,05)$.

${ }^{1} R A$ : reação acrossômica

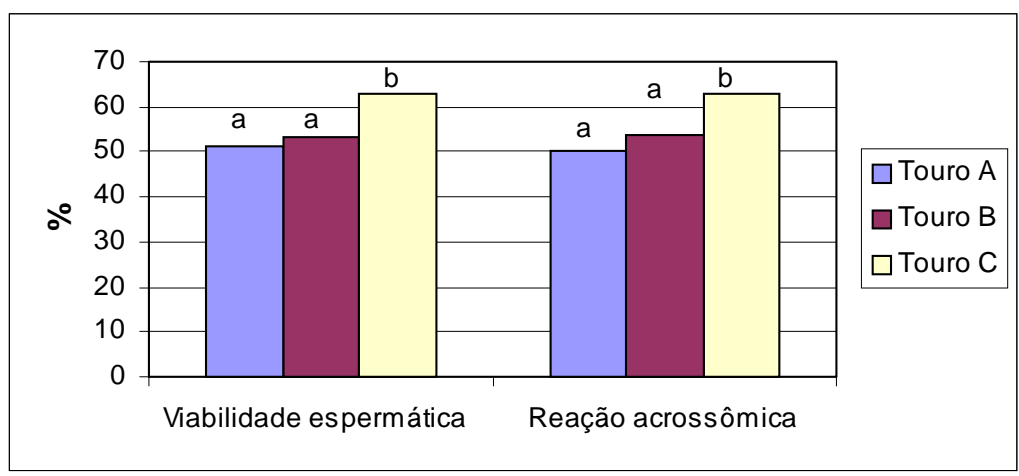

Figura 1 - Percentagem de espermatozóides viáveis e com reação acrossômica para os touros A, B e C, da raça Guzerá, após a capacitação in vitro. Médias com letras diferentes entre colunas diferem entre si $(P<0,05)$. se ligar ou incorporar esses complexos à sua membrana plasmática (Blottner et al., 1990; McCauley et al., 1996). Os HPBs aumentam a habilidade do espermatozóide em sofrer reação acrossômica na presença de heparina ou proteínas da zona pelúcida (Bellin et al., 1996; McCauley et al., 1996). Além disso, existem diferentes tipos de HPB que se incorporam aos espermatozóides, podendo variar de acordo com o seu peso molecular e afinidade pela heparina (Bellin et al., 1996). Portanto, espermatozóides de touros de alta fertilidade tendem a sofrer reação acrossômica com mais freqüência (Blottner et al., 1990; Rajamahendran et al., 1994), provavelmente por terem HPBs com maior afinidade à heparina.

A utilização de procedimentos para avaliar a capacita-ção espermática in vitro antes de se utilizar o sêmen para a FIV, torna a produção de embriões in vitro mais eficiente. Isso pode ser feito por meio de exames de RA a viabilidade espermática. Como observado neste experimento, diferenças na capacitação espermática em touros da raça Guzerá podem ser identificadas pela avaliação da RA e viabilidade. ria mais apto para a FIV, levando-se em consideração que haverá uma correlação positiva entre a taxa de não-retorno aos 90 dias e as taxas de RA e viabilidade (Whitfield e Parkinson, 1992). Tanghe et al. (2002) observaram que sêmen com maior viabilidade ao final da incubação in vitro promove maior taxa de oócitos fecundados.

A diferença observada entre os touros pode estar relacionada com diferentes níveis de produção e secreção de complexos protéicos com afinidade à heparina (denominados HBP) no fluido seminal, e (ou) à capacidade do espermatozóide em

\section{Referências}

BELLIN, M. E.; HAWKINS, H. E.; AX, R. L. Fertility of range beef bulls grouped according to presence or absence of heparin-binding proteins in sperm membranes and seminal fluid. Journal of Animal Science, v. 1, n. 7, p. 2441-2448, 1994.

BELLIN, M. E.; HAWKINS, H. E.; OYARZO, J. N.; RUSSEL, J. V.; AX, R. $\mathrm{L}$. Monoclonal antibody detection of heparin-binding proteins on sperm corresponds to increased fertility of bulls. Journal of Animal Science, v. 74, p. 173-182, 1996.

BLOTTNER, S.; NEHRING, H.; TORNER H. Individual differences in capacitation of bull spermatozoa by heparin in vitro: relationship to fertility. Theriogenology, v. 34, n. 3, p. 619-628, 1990.

COX, J. F.; SARAVIA, F.; BRIONES, M.; SANTA MARIA, A. Dosedependent effect of heparin on fertilizing ability of goat spermatozoa. Theriogenology, v. 44, p. 451-460, 1994.

DASGUPTA, S.; MILLS, C. L.; FRASER, L. R. A possible role of $\mathrm{Ca}^{2+}$ Tpase in human sperm capacitation. Journal Reproduction Fertility, v. 102, p. 107-116, 1994.

DOTT, H. M.; FOSTER, G. C. A technique for studying the morfology of mammalian spermatozoa which are eosinophilic in a diferencial lifedead stain. Journal Reproduction Fertility, v. 29, p. 443-445, 1972.

\section{Conclusões}

A concentração de $10 \mathrm{mg} / \mathrm{ml}$ de heparina é suficiente para aumentar a capacitação espermática e, conseqüentemente, a taxa de reação acrossômica do sêmen de touros Guzerá, sem afetar sua viabilidade.

Exames de RA e viabilidade espermática podem auxiliar na avaliação de sêmen de touros Guzerá, antes de utilizá-los em procedimentos de FIV, identificando diferenças existentes durante a capacitação espermática in vitro.

FUKUI, Y.; SONOYAMA, T.; MOCHIZUKI, H.; ONO, H. Effects of heparin dosage and sperm capacitation time on in vitro fertilization and cleavage of bovine oocytes matured in vitro. Theriogenology, v. 34, p. 579-591, 1990.

GALINA, C. S.; ORIHUELA, A.; RUBIO, I. Reproductive physyology in zebu cattle, characteristics related to estrous expression and performance of bulls utilized in natural mating. In: CONGRESSO BRASILEIRO DE REPRODUÇÃO ANIMAL, 2. Belo Horizonte, MG, 1995. Anais... Belo Horizonte, MG: Colégio Brasileiro de Reprodução animal, 1995. p. 46-61.

GLIEDT, D. W.; ROSENKRANS, C. F.; RORIE, R. W.; RAKES, J. M. Effects of oocyte maturation length, sperm capacitation time, and heparin on bovine embryo development. Journal Dairy Science, v. 79, p. 532535, 1996.

LECLERC, P.; LANGLAIS, J.; LAMBERT, R. D.; SIRARD, M. A.; CHAFOULEAST, J.G. Effect of heparin on the expression of calmodulinbinding proteins in bull spermatozoa. Journal Reprodution Fertility, v. 85, p. 615-622, 1989.

MARK, J. L.; AX, R. L. Relationship of nonreturn rates of dairy bulls to binding affinity of heparin to sperm. Journal of Dairy Science, v. 68, p. 2078, 1985. 
McCAULEY, T. C.; BELLIN, M. E.; AX, R. L. Localization of a heparin-binding protein to distinct regions of bovine sperm. Journal Animal Science, v. 74, p. 429-438, 1996.

MILLER, D. J.; HUNTER, A. G. Effect of osmolality and glycosaminoglycans on motility, capacitation, acrosome reaction, and in vitro fertilizability of bovine ejaculated spermatozoa. Journal Dairy Science, v. 69, p. 2915-2924, 1986.

MILLER, D. J.; WINER, M. A.; AX, R. L. Heparin-binding proteins from seminal plasma bind to bovine spermatozoa and modulate capacitation by heparin. Biology of Reproduction, v. 12, p. 899, 1990.

MUNRO, R. K. The superovulatory response of Bos taurus and Bos indicus cattle following treatment with follicle stimulating hormone and progesterone. Animal Reproduction Science, v. 11, p. 91-97, 1986.

PARRISH, J. J.; SUSKO-PARRISH, J.; WINER, M. A.; FIRST, N. L. Capacitation of bovine spermatozoa by heparin. Biology of Reproduction, v. 38, p. 1171-1188, 1988.

PEREIRA, R. J. T. A.; TULI, R. K.; WALLENHORST, S.; HOLTZ, W. The Effect of Heparin, Caffeine and Calcium lonophore A 23187 on in vitro Induction of the Acrosome Reaction in FrozenThawed Bovine and Caprine Spermatozoa. Theriogenology, v. 54, n. 2, p. 185-192, 2000.

PÉREZ, L. J.; VALCÁRCEL, A.; DE LAS HERAS, M. A.; MOSES, D.; BALDASSARE, $H$. The storage of pure ram semen at room temperature results in capacitation of a subpopulation of spermatozoa. Theriogenology, v. 47, n. 2, p. 549-558, 1997.
RAJAMAHENDRAN, R.; AMBROSE, J. D.; LEE, C. Y. G. Antihuman sperm monoclonal antibody HS-11: a potential marker to detect bovine sperm capacitation and acrosome reaction in vitro. Journal Reproduction Fertility, v. 101, p. 539-545, 1994.

RANDEL, R. D. Seasonal effects on female reproductive functions in the bovine (Indian breed). Theriogenology, v. 21, p. 170-185, 1984.

SÁ, W. F.; LOPES, C. F.; CAMARGO, L S.; FERREIRA, A. M.; RAMOS, A. A.; VIANA, J. H. M.; NOGUEIRA, L. A. Avaliação da capacitação espermática in vitro pela viablidade e reação acrossômica. Revista Brasileira de Ciência Veterinária, v. 9, n. 2, p. 68-71, 2002.

TANGHE, S.; VAN SOOM, A.; STERCKX, V.; DE KRUIF, A. Assessment of Different Sperm Quality Parameters to Predict in vitro Fertility of Bulls. Reproduction Domestic Animal, v. 37, n. 3, p. 127-32, 2002.

THÉRIEN, I.; BLEAU, G.; MANJUNATH, P. Phosphatidylcholinebiding proteins of bovine seminal plasma modulate capacitation of spermatozoa by heparin. Biology of Reproduction, v. 52, p. 1372-1379, 1995.

WAY, A. L.; HENAULT, M. A.; KILLIAN, G. J. Comparison of four staining methods for evaluating acrosome status and viability of ejaculated and cauda epididymal bull spermatozoa. Theriogenology, v. 43, p. 1301-1316, 1994.

WHITFIELD, C. H.; PARKINSON, T. J. Relastionship between fertility of bovine semen and in vitro induction of acrosome reactions by heparin. Theriogenology, v. 38, p. 11-20, 1992. 